\title{
Effective utilization of waste cathode ray tube glass-Crystalline silicotitanate synthesis
}

\author{
Mengjun Chen ${ }^{\mathrm{a}, \mathrm{b}}$, Fu-Shen Zhang ${ }^{\mathrm{a}, *}$, Jianxin Zhu ${ }^{\mathrm{a}}$ \\ a Research Center for Eco-Environmental Sciences, Chinese Academy of Sciences, 18 Shuangqing Road, Beijing 100085, China \\ ${ }^{\mathrm{b}}$ Key Laboratory of Solid Waste Treatment and Resource Recycle (SWUST), Ministry of Education, Southwest University of Science and Technology, Mianyang 621010, China
}

\section{A R T I C L E I N F O}

\section{Article history:}

Received 16 January 2010

Received in revised form 26 May 2010

Accepted 30 May 2010

Available online 4 June 2010

\section{Keywords:}

WEEE

Supercritical water

Microporous silicotitanate sorbent

Sol-gel

Adsorption

\begin{abstract}
A B S T R A C T
A novel process for crystalline silicotitanate (CST) synthesis was developed using waste cathode ray tube (CRT) panel glass as silicon source. The key trait of the process was to extract most of the silicon out of the glass for CST preparation, but leave Ba and $\mathrm{Sr}$ in the residue which had the potential to be employed as raw material for metallic Ba and Sr metallurgy. In the synthesis process, waste CRT panel glass was firstly treated by supercritical water (SCW)-NaOH solution for Si extraction, then sol-gel and hydrothermal treatments were used for CST preparation. $80 \%$ of $\mathrm{Si}$ in the glass could be extracted into the solution, while $\mathrm{Sr}$ and $\mathrm{Ba}$ were enriched in the residue in the form of $\mathrm{Sr}_{2} \mathrm{SiO}_{4}$ and $\mathrm{Ba}_{2} \mathrm{Si}_{3} \mathrm{O}_{8}$, respectively. $\mathrm{Sr}$ and Ba contents in the residue were 2-3 times higher than those in the raw glass. SEM, XRD and TEM results indicated that CST was successfully synthesized. Ion exchanging experiments showed that the batch distribution coefficient of the synthesized CST to $\mathrm{Cs}^{+}$was up to $1.2 \times 10^{4} \mathrm{~mL} / \mathrm{g}$ at $\mathrm{pH} 0.26$.
\end{abstract}

(C) 2010 Elsevier B.V. All rights reserved.

\section{Introduction}

In recent years, the replacement of cathode ray tube (CRT) televisions and monitors by liquid crystal display (LCD), light emitting diode (LED) panel or plasma display panel (PDP) is particularly significant, causing millions of units of waste CRT. CRT glasses contain poisonous heavy metals [1]. Lead $(\mathrm{Pb})$, in particular, represents a serious threat to the environment and human health [2]. Therefore, technologies for CRT glass treatment and reutilization are urgently required, especially in China, where is the destination of more than 70\% of the world's Waste Electrical and Electronic Equipment (WEEE) [3].

Thus far, many studies have been carried out on CRT glass treatments [4-21]. In previous years, CRT glass was generally cleaned, sorted and sent to glass manufacturers for new CRT glass manufacturing. Currently, due to the extreme reduction in CRT production, much attention had been attracted to the recycle of CRT glass as a secondary raw material, such as reutilization as glaze [4,5], glass ceramic [6], foam glass [7-12] and glass matrix composites [13-16]. Nevertheless, these methods paid little attention to the environmental security, since the prepared products still contain dangerous heavy metals, which should be removed or separated. Therefore, technologies for lead extraction were proposed, such as

\footnotetext{
* Corresponding author. Tel.: +86 10 62849515; fax: +86 1062849515 .

E-mail address: fszhang@rcees.ac.cn (F.-S. Zhang).
}

ultrasonically enhanced leaching [19], subcritical water-aided acid leaching [20] and vacuum-aided pyro-metallurging [21]. However, these extraction methods only focused on extracting/recycling lead from lead containing CRT funnel glass. Thus far, very limited information is available on environment benign technologies for recycling $\mathrm{Ba} / \mathrm{Sr}$ from $\mathrm{Ba} / \mathrm{Sr}$ containing CRT panel glass. According to our recent study, this type of glass was splendid for crystalline silicotitanate (CST) synthesis.

CST $\left(\mathrm{Na}_{2} \mathrm{Ti}_{2} \mathrm{O}_{3} \mathrm{SiO}_{4} \cdot 2 \mathrm{H}_{2} \mathrm{O}\right)$, with a sitinakite-like structure, jointly developed by Sandia National Laboratories and Texas A\&M University [22], is a kind of useful inorganic ion exchangers for removing ${ }^{137} \mathrm{Cs}$ and ${ }^{90} \mathrm{Sr}$ radionuclides from defense wastes, since it is highly selective for $\mathrm{Cs}$ and $\mathrm{Sr}$ over a broad $\mathrm{pH}$ range and in the presence of competitive ions (i.e. $\mathrm{Na}, \mathrm{Ca}$ ) [23-29]. In addition, the cesium trapped CST can be directly immobilized to a ceramic or glass form for final disposal [30]. Therefore, CST has been recognized as the preferable choice for removing $\mathrm{Cs} / \mathrm{Sr}$ from nuclear waste, and it was awarded a 1996 R\&D 100 award as "one of the 100 most technologically significant product of the year" [31,32]. Thus far, many papers have been published on CST synthesis [33-35], generally using titanium isopropoxide/titanium tetrachloride as titanium source and tetraethyl orthosilicate/silicon ethoxide/colloidal silica as silicon source. However, reports on preparing CST using waste CRT glass as silicon source are considerably few.

In this paper, CRT panel glass was used as silicon source for CST synthesis. The proposed process consisted of silicon extraction from CRT panel glass, gel formation and CST preparation. The separated 
Table 1

Chemical composition of the investigated panel glass by X-ray fluorescence (XRF).

\begin{tabular}{lllllll}
\hline Oxide & $\mathrm{SiO}_{2}$ & $\mathrm{PbO}$ & $\mathrm{K}_{2} \mathrm{O}$ & $\mathrm{Na}_{2} \mathrm{O}$ & $\mathrm{Al}_{2} \mathrm{O}_{3}$ & $\mathrm{SrO}$ \\
\hline wt.\% & 59.42 & 1.16 & 7.88 & 5.72 & 1.92 & 10.4 \\
Oxide & $\mathrm{CaO}$ & $\mathrm{BaO}$ & $\mathrm{MgO}$ & $\mathrm{ZrO}_{2}$ & $\mathrm{Fe}_{2} \mathrm{O}_{3}$ & $\mathrm{P}_{2} \mathrm{O}_{5}$ \\
\hline wt.\% & 0.32 & 9.67 & - & 2.32 & - & - \\
\hline
\end{tabular}

liquid and solid after SCW-NaOH treatment were examined, and the synthesized CST was characterized for $\mathrm{Cs}^{+}$removal.

\section{Experimental}

\subsection{Materials}

Panel glasses of PC monitor, provided by Huaxing Environmental Protection Corporation, was firstly ball-milled to powders (no more than 80 mesh), which was described elsewhere [21]. Chemical composition of the glass powder was examined by XRF and the results were presented in Table 1 . Other materials used in the experiments were all analytical reagents unless otherwise mentioned.

\subsection{Silicon source preparation}

A stainless autoclave was employed for SCW-NaOH treatment. The autoclave was made of $316 \mathrm{~L}$ stainless alloy with a capacity of $200 \mathrm{~mL}$. The pressure inside the autoclave changed within 32-42 MPa along with the temperature varying from $573 \mathrm{~K}$ to $723 \mathrm{~K}$. In a typical SCW-NaOH treatment process, $5 \mathrm{~g}$ of the panel glass powder (fixed), a certain amount of $\mathrm{NaOH}$ and $120 \mathrm{~mL}$ of distilled water were mixed in the stainless autoclave. The treatment time was varied from $1 \mathrm{~h}$ to $10 \mathrm{~h}$, and the treatment temperature was kept at $673 \mathrm{~K}$. NaOH adding amount investigated were $0 \mathrm{~g}, 1 \mathrm{~g}, 2 \mathrm{~g}$, $5 \mathrm{~g}, 8 \mathrm{~g}, 10 \mathrm{~g}, 15 \mathrm{~g}$ and $20 \mathrm{~g}$. After the treatment, the autoclave was immediately cooled using an electronic fan. Then the suspension was centrifuged at $3000 \mathrm{rpm}$ for $20 \mathrm{~min}$ to separate the liquid and solid, and the supernatant was filtrated through $0.45 \mu \mathrm{m}$ membranes. At last, the filtrated liquids were used as the silicon source for CST preparation.

The filtrated liquids were examined by inductively coupled plasma optical emission spectrometer (ICP-OES, OPTIMA 2000), while the residues, after the centrifugation, were dried at $378 \mathrm{~K}$, digested by $\mathrm{HNO}_{3}-\mathrm{HClO}_{4}-\mathrm{HF}$ [36] and analyzed by ICP-OES. Silicon extraction rates were calculated according to the silicon content before and after $\mathrm{SCW}-\mathrm{NaOH}$ treatment process. Other elements, such as $\mathrm{Na}^{+}, \mathrm{K}^{+}, \mathrm{Pb}^{2+}, \mathrm{Sr}^{2+}, \mathrm{Ba}^{2+}$ and $\mathrm{Al}^{3+}$, were also examined to determine their distributions in the liquids and residues after the treatment. The residues were also investigated by X-ray diffraction (XRD) using the Ni-filtered $\mathrm{Cu} \mathrm{K} \alpha$ radiation on a Rigaku D/MAX2500 diffractometer.

\subsection{CST preparation}

First, titanium tetrachloride was dropped into the stirring absolute ethyl alcohol. The volume ratio of $\mathrm{TiCl}_{4}: \mathrm{CH}_{3} \mathrm{CH}_{2} \mathrm{OH}$ was $1: 4$. Then a homogenous yellow solution was obtained. The solution was then dropped into the strongly agitating silicon source obtained according to Section 2.2, and a gel was obtained. After lying overnight, the gel was loaded into a Teflon-lined pressure vessel. The Teflon bomb was then placed in a stainless steel vessel, sealed, and then heated in a $443 \mathrm{~K}$ oven for 7 days. The white solid resulting from the hydrothermal treatment was filtrated and washed with large quantities of water in an attempt to wash away sodium excess. It should be pointed out that all theses liquids were col-

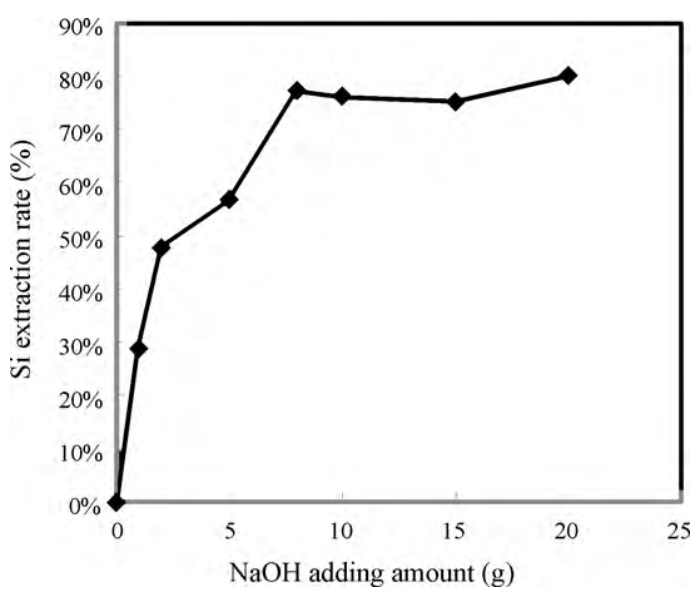

Fig. 1. Effect of $\mathrm{NaOH}$ amount on $\mathrm{Si}$ extraction percentage. Other conditions: temperature $=673 \mathrm{~K}$; treatment time $=3 \mathrm{~h}$.

lected and treated to fulfill the regulations before discharge. At last, the white solid was dried at $333 \mathrm{~K}$. Scanning electron microscope (SEM, S-3000N), XRD, and transmission electron microscopy (TEM, H-7500) were employed to examine the surface morphology, crystalline property and particle size of the prepared CST.

\subsection{Sorption experiments}

The prepared CST was further characterized by sorption experiments. The purification of nuclear waste effluents using CST inorganic ion exchangers always involves column exchange, and the batch distribution coefficient $\left(K_{\mathrm{d}}\right)$ represents the maximum processing capacity in column operation [37]. Therefore, $K_{\mathrm{d}}$ was also used in this study. Under ideal conditions, $K_{\mathrm{d}}$ is calculated from Eq. (1)

$K_{\mathrm{d}}=\left(C_{0}-C_{\mathrm{e}}\right) / C_{\mathrm{e}} \cdot V / M$

where $C_{0}$ and $C_{\mathrm{e}}$ are, respectively, the initial and equilibrium concentrations of the radionuclide of interest and $V / M$ is the solution volume to exchanger mass ratio. The distribution coefficients obtained in this study were the mean value of two experiments.

The prepared CSTs were accurately weighed $(10 \mathrm{mg})$ and placed in contact with $20 \mathrm{~mL}$ of $\mathrm{Cs}^{+}$solution $(50 \mathrm{ppm}, \mathrm{pH}$ in the range of $0-14)$. The solution/solid mixtures were equilibrated for 2 days on a mineralogical roller. The suspensions were then centrifuged and filtrated through $0.2 \mu \mathrm{m}$ membranes, and the filtrates were analyzed for $\mathrm{Cs}^{+}$by an inductively coupled plasma mass spectrometer (ICP-MS, Plasma Quad 3). $K_{\mathrm{d}}$ was calculated according to Eq. (1). All samples were counted at the same geometry, and the measurement errors were around $\pm 1 \%$.

\section{Results and discussion}

\subsection{SCW-NaOH treatment process}

$\mathrm{Si}$ is generally extracted by $\mathrm{NaOH}$ fusion, though this method is complicated and its Si extraction rate is limited. Comparatively, SCW-NaOH process could greatly enhance the extraction efficiency, since glass network could be broken down efficiently by supercritical water, as reported by a previous study [38].

The effect of $\mathrm{NaOH}$ amount on silicon extraction rate by the SCW-NaOH process is shown in Fig. 1. When no $\mathrm{NaOH}$ was added in the SCW-NaOH system, the CRT glass powders, no more than 80 mesh, were agglomerated to a single brick and it was hard to take out from the autoclave, indicating that some mineralization process may occur. Furthermore, it can be seen from Fig. 1 that, 


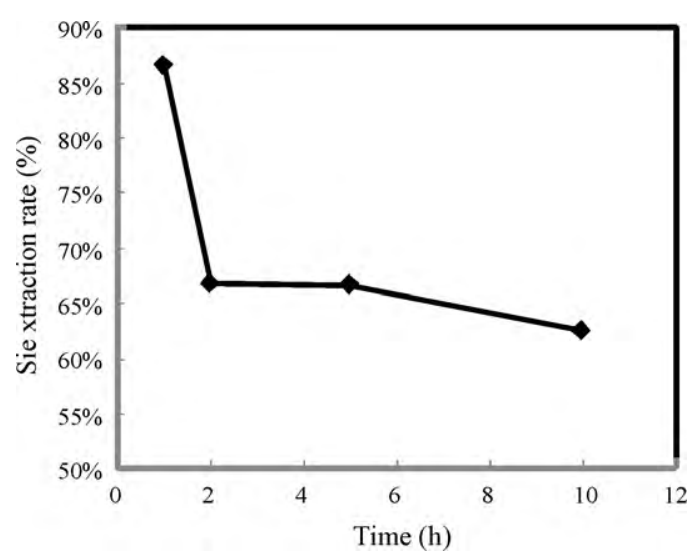

Fig. 2. Effect of treatment time on Si extraction percentage. Other conditions: temperature $=673 \mathrm{~K} ; \mathrm{NaOH}=5 \mathrm{~g}$.

when $\mathrm{NaOH}$ amount was between $0 \mathrm{~g}$ and $8 \mathrm{~g}$, the silicon extraction rate increased significantly with the increase of $\mathrm{NaOH}$ amount, e.g. increased from $28.84 \%$ at $1 \mathrm{~g}$ to $77.17 \%$ at $8 \mathrm{~g}$, then it reached a plateau value when $\mathrm{NaOH}$ adding amount was higher than $8 \mathrm{~g}$. The results indicated that, when $\mathrm{NaOH}$ was no more than $8 \mathrm{~g}, \mathrm{OH}^{-}$ amount in the treatment system increased greatly along with the increase of $\mathrm{NaOH}$, leading to a high broken efficiency of $=\mathrm{Si}-\mathrm{O}-\mathrm{Si} \equiv$ bonds, hence silicon could easily be transferred to the liquid phase and silicon extraction rate increased. When $\mathrm{NaOH}$ adding amount was higher than $8 \mathrm{~g}, \mathrm{OH}^{-}$amount in the treatment system was sufficient to break $\equiv \mathrm{Si}-\mathrm{O}-\mathrm{Si} \equiv$ bonds, leading to a slight increase of silicon extraction rate (Fig. 1).

Fig. 2 gives the effect of treatment time on silicon extraction rate by the SCW-NaOH process. When the treatment time increased from $1 \mathrm{~h}$ to $2 \mathrm{~h}$, silicon extraction rate decreased greatly from $86.54 \%$ to $66.72 \%$. Further extending the treatment time, the silicon extraction rate decreased slowly. This could be attributed to that, in a related short treatment time, SCW-NaOH could destroy the glass network efficiently, promoting silicon extraction. But the extracted silicon could mineralize with the extension of treatment time in the system of high pressure (about $40 \mathrm{MPa}$ ) and high temperature (673 K) [19], forming insoluble silicate minerals hence silicon extraction decreased.

\subsection{Characterization of the liquid and residue after $\mathrm{SCW}-\mathrm{NaOH}$ treatment}

The composition of the filtrated liquid and the residue was analyzed, when the panel glass was treated by SCW-NaOH at $673 \mathrm{~K}$ for $3 \mathrm{~h}$ with $\mathrm{NaOH}$ adding amount of $5 \mathrm{~g}$, and the results are given in Tables 2 and 3. Fig. 3 shows the XRD pattern of the residue.

From Table 2, it can be found that $\mathrm{Na}^{+}$concentration in the liquid was the highest, up to $23.38 \mathrm{~g} / \mathrm{L}$, followed by silicon, around $9.65 \mathrm{~g} / \mathrm{L}$, while $\mathrm{Pb}^{2+}$ in the solution was $2.84 \mathrm{mg} / \mathrm{L} . \mathrm{K}^{+}$and $\mathrm{Al}^{3+}$ in the solution were supposed to come from the glass network after the network

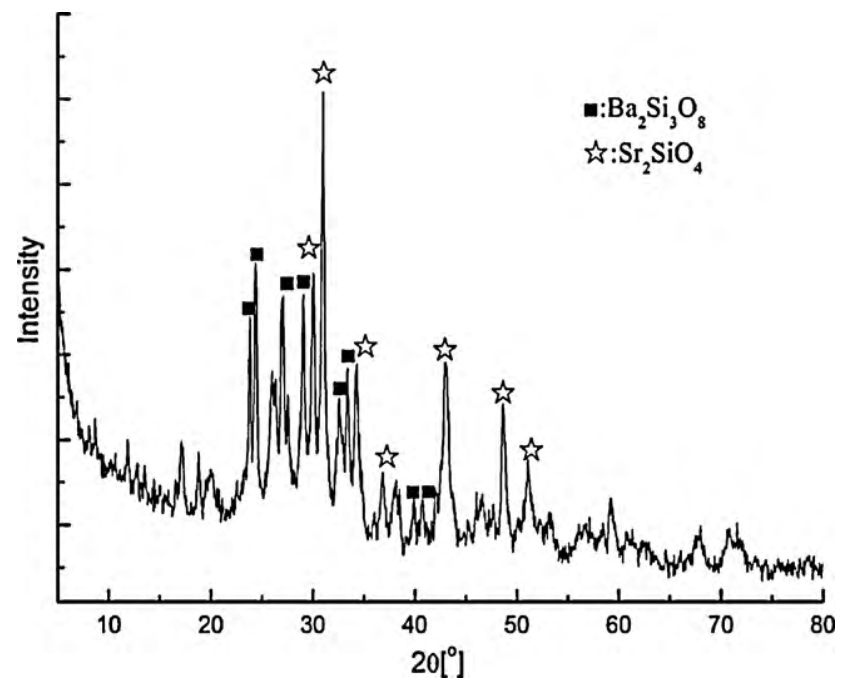

Fig. 3. XRD patterns of the residue after supercritical water-NaOH treatment. Other conditions: panel glass $=5 \mathrm{~g}, \mathrm{NaOH}=5 \mathrm{~g}$, temperature $=673 \mathrm{~K}$; treatment time $=3 \mathrm{~h}$.

destruction. $\mathrm{Pb}^{2+}$ in the solution could be attributed to that lead oxides were slightly dissolved by $\mathrm{OH}^{-}$since lead oxides are slightly amphoteric. It can also be found from Table 2 that no strontium and barium ions can be detected by ICP-OES, indicating that, after the $\mathrm{SCW}-\mathrm{NaOH}$ extraction process, $\mathrm{Sr}$ and Ba were not transferred to the liquid phase but enriched in the residue.

Considering the composition of the investigated panel glass, it can be seen from Table 3 that the content of $\mathrm{PbO}, \mathrm{Na}_{2} \mathrm{O}, \mathrm{Al}_{2} \mathrm{O}_{3}$, $\mathrm{SrO}$ and $\mathrm{BaO}$ in the residue increased, while those of $\mathrm{K}_{2} \mathrm{O}$ and $\mathrm{SiO}_{2}$ decreased. $\mathrm{SrO}$ and $\mathrm{BaO}$ in the residue were about 3 times of those containing in the investigated panel glass, while $\mathrm{SiO}_{2}$ in the residue decreased to $26.63 \%$ from $59.42 \%$ in the investigated panel glass. To further check the elements distribution, the mass balance analysis of $\mathrm{Pb}, \mathrm{Ba}, \mathrm{Sr}, \mathrm{Na}, \mathrm{K}, \mathrm{Al}$ and $\mathrm{Si}$ containing in the investigated panel glass, and containing in the filtrated liquid and residue after $\mathrm{SCW}-\mathrm{NaOH}$ treatment were conducted. It was found that, after SCW-NaOH treatment, about $90 \%$ of K, $50 \%$ of $\mathrm{Al}$ and $80 \%$ of Si were transferred from solid to liquid. From Fig. 3, it can be found that strontium and barium containing in the investigated panel glass were converted from amorphous to crystalline, mainly $\mathrm{Ba}_{2} \mathrm{Si}_{3} \mathrm{O}_{8}$ and $\mathrm{Sr}_{2} \mathrm{SiO}_{4}$.

When the waste panel glass was treated by $\mathrm{SCW}-\mathrm{NaOH}$, most of its silicon entered the liquid phase, while $\mathrm{Sr}$ and Ba were enriched in the residues. Meanwhile, the silicon liquid can be used as silicon source to synthesize function materials such as molecular sieves or other chemical substances. On the other hand, $\mathrm{BaO}$ and $\mathrm{SrO}$ in the residue increased to 26.28 and $28.26 \mathrm{wt}$.\% from 9.67 and $10.4 \mathrm{wt} . \%$, respectively, which has the potential to be used as the raw material for metallic Ba and Sr metallurgy. To identify this possibility, studies are currently under investigation in our lab. In addition, studies are carried out to understand whether $\mathrm{Pb}$ containing in the residue will

Table 2

Solution composition after SCW-NaOH treatment of color panel glass ( $5 \mathrm{~g}$ glass and $5 \mathrm{~g} \mathrm{NaOH}$ at $673 \mathrm{~K}$ for $3 \mathrm{~h}$ ).

\begin{tabular}{|c|c|c|c|c|c|c|c|}
\hline Element & $\mathrm{Pb}^{2+}$ & $\mathrm{K}^{+}$ & $\mathrm{Na}^{+}$ & $\mathrm{Al}^{3+}$ & $\mathrm{Sr}^{2+}$ & $\mathrm{Ba}^{2+}$ & $\mathrm{Si}$ \\
\hline Concentration & $2.84 \mathrm{mg} / \mathrm{L}$ & $1.29 \mathrm{~g} / \mathrm{L}$ & $23.38 \mathrm{~g} / \mathrm{L}$ & $0.23 \mathrm{~g} / \mathrm{L}$ & - & - & $9.65 \mathrm{~g} / \mathrm{L}$ \\
\hline
\end{tabular}

Table 3

Residue composition after SCW-NaOH treatment of color panel glass ( $5 \mathrm{~g}$ glass and $5 \mathrm{~g} \mathrm{NaOH}$ at $673 \mathrm{~K}$ for $3 \mathrm{~h}$ ).

\begin{tabular}{|c|c|c|c|c|c|c|c|}
\hline Oxide & $\mathrm{PbO}$ & $\mathrm{K}_{2} \mathrm{O}$ & $\mathrm{Na}_{2} \mathrm{O}$ & $\mathrm{Al}_{2} \mathrm{O}_{3}$ & $\mathrm{SrO}$ & $\mathrm{BaO}$ & $\mathrm{SiO}_{2}$ \\
\hline wt.\% & 2.99 & 0.56 & 12.88 & 2.40 & 28.26 & 26.28 & 26.63 \\
\hline
\end{tabular}




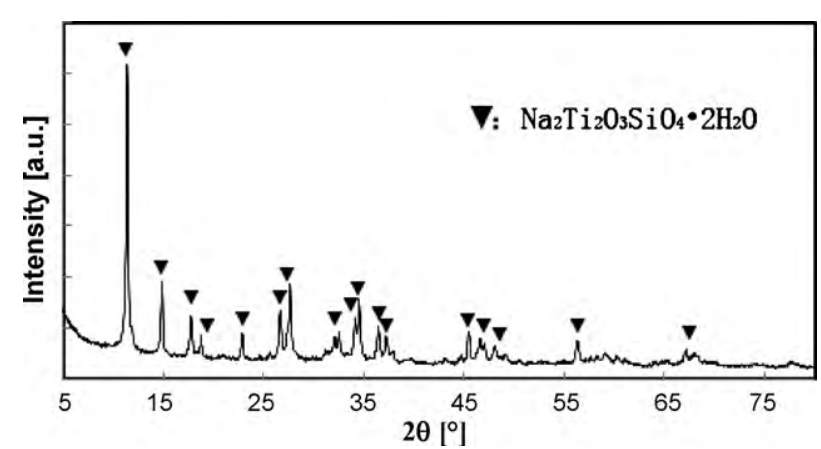

Fig. 4. XRD patterns of the crystalline silicotitanate.

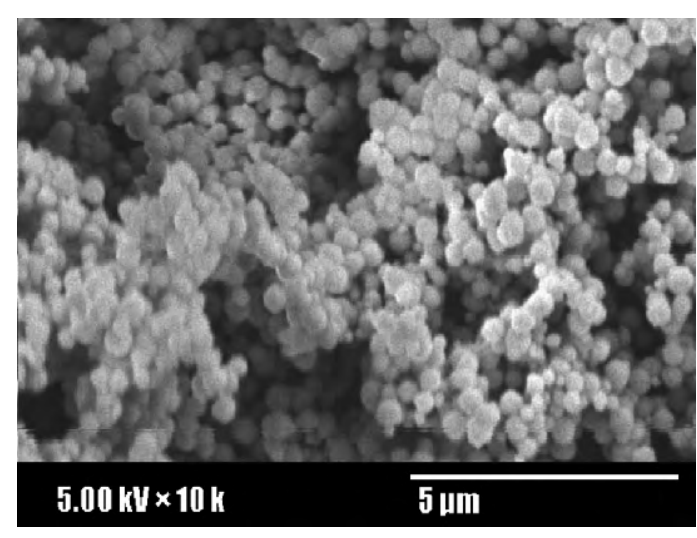

Fig. 5. SEM photographs of the synthesized CST(10,000 $\times)$.

affect the metallurgic process and to examine whether Pb containing in the residue will result in a secondary contamination, since $\mathrm{PbO}$ in the residue was enriched from $1.16 \mathrm{wt}$.\% to $2.99 \mathrm{wt} . \%$.

\subsection{CST characterization}

The filtrated liquid after SCW-NaOH treatment was used as silicon source for CST preparation. Si concentration of the filtrated liquid was about $9.65 \mathrm{~g} / \mathrm{L}$. For each preparation, $50 \mathrm{~mL}$ of the liquid, $5 \mathrm{~mL}$ of $\mathrm{TiCl}_{4}-\mathrm{CH}_{3} \mathrm{CH}_{2} \mathrm{OH}$ were used, and CST synthesis was strictly based on Section 2.3.

Fig. 4 shows the XRD patterns of the synthesized CST. It can be found that the baseline was flat and there were no any amorphous features, indicating that the products were well crystallized. An intensive fraction peak with low $2 \theta$ value around $11^{\circ}$ showed the crystal structure of CST, and all the peaks in the XRD patterns were well indexed to PDF 47-0591 (CST).

The synthesized product was further characterized by SEM to examine its surface morphology. From Fig. 5, it can be seen that the prepared material was fully crystallized, and the particles were

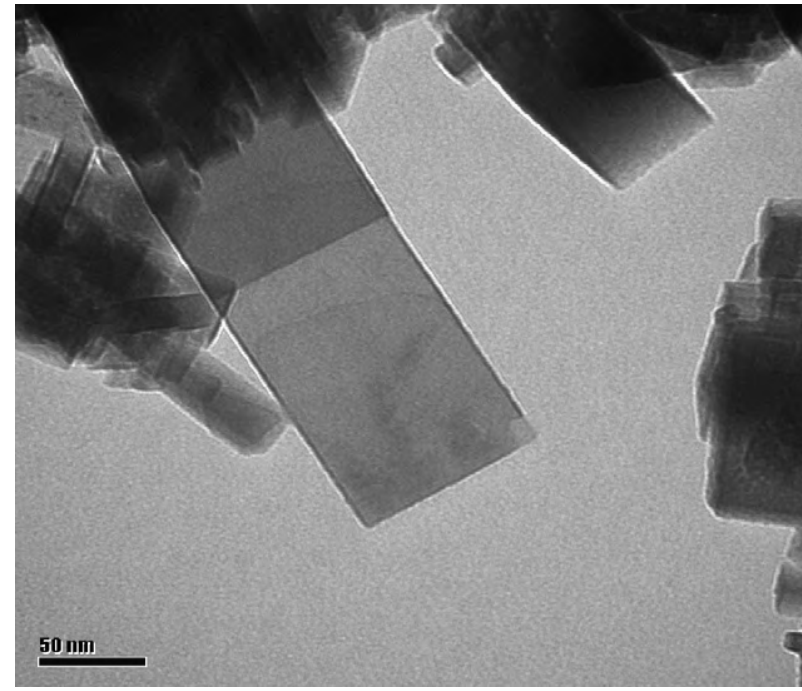

Fig. 7. TEM micrograph of the crystalline silicotitanate $(300,000 \times)$.

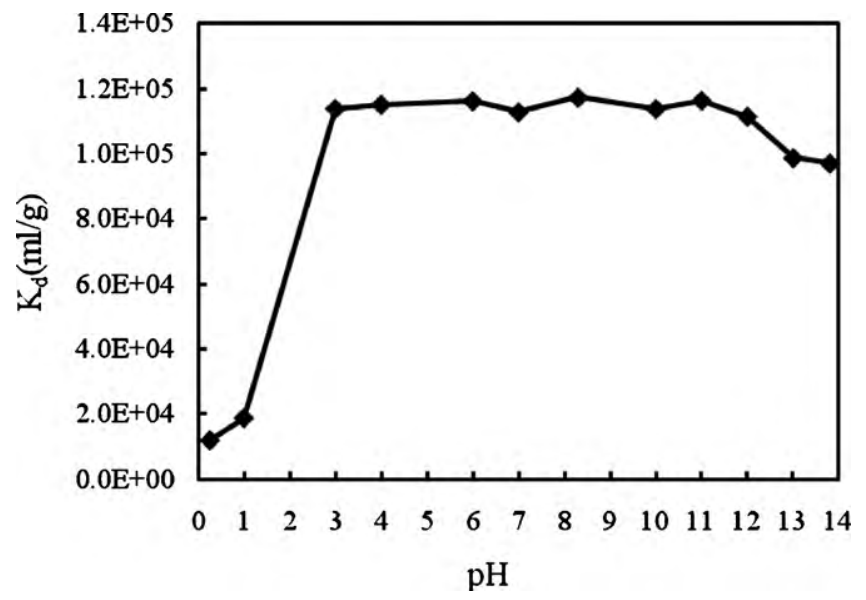

Fig. 8. Effect of pH on $K_{\mathrm{d}}\left(\mathrm{Cs}^{+}\right)$. Other conditions: $10 \mathrm{mg}$ CST in $20 \mathrm{~mL}$ of $\mathrm{Cs}^{+}(50 \mathrm{ppm})$, 2 days.

tiny, around $0.5 \mu \mathrm{m}$, and in ball shape. According to the TEM results shown in Fig. 6, the ball shape CST, shown in SEM pictures, was actually the secondary particles formed by the agglomeration of initial CST crystal particles, indicating that the initial CST particles were seriously agglomerated. Fig. 7 indicates that the cross-section of the synthesized CST was rectangle.

Fig. 8 illustrates the effect of $\mathrm{pH}$ on $\mathrm{Cs}^{+}$removal by CST at ambient temperature. It can be found that CST showed an extremely high selectivity to $\mathrm{Cs}^{+}$in the whole examined $\mathrm{pH}$ range, though the values of $K_{\mathrm{d}}$ were relatively lower in a strong acidic environment, e.g. only $1.2 \times 10^{4} \mathrm{~mL} / \mathrm{g}$ at $\mathrm{pH} 0.26$. When $\mathrm{pH}$ was in the range of

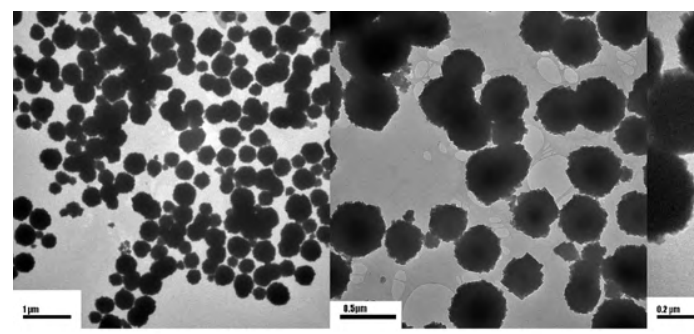

(a) (b)

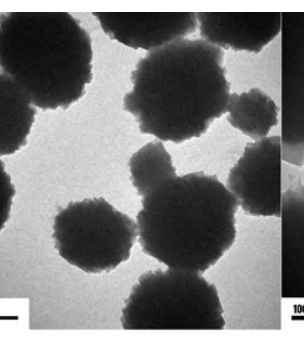

(c)

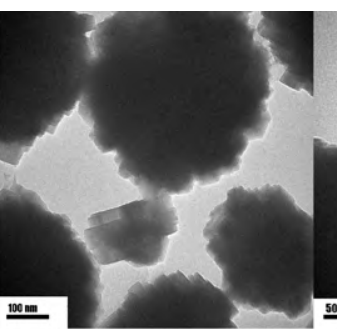

(d)

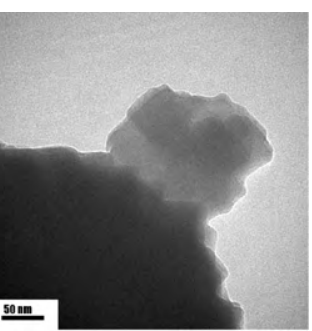

(e)

Fig. 6. TEM micrograph of the crystalline silicotitanate (a: $20,000 \times$, b: $50,000 \times$, c: $100,000 \times, d: 200,000 \times$, e: $400,000 \times$ ). 
$0-3, K_{\mathrm{d}}$ was significantly increased from $1.2 \times 10^{4} \mathrm{~mL} / \mathrm{g}$ at $\mathrm{pH} 0.26$ to $1.1 \times 10^{5} \mathrm{~mL} / \mathrm{g}$ at $\mathrm{pH} 3$; and it almost kept constant when $\mathrm{pH}$ was in the range of $3-12$. When $\mathrm{pH}$ value was increased to $14, K_{\mathrm{d}}$ decreased to around $1.0 \times 10^{5} \mathrm{~mL} / \mathrm{g}$. This trend is very similar to the CSTs prepared using pure organic substances [39], but the distribution coefficient of CST prepared in this experiment using waste CRT panel glass as silicon source was about 100 times higher than those of CSTs prepared by pure organic substances [39], possibly because that the $\mathrm{Cs}^{+}$containing solution in this experiment was simulated, without any other competitive ions such as $\mathrm{Na}^{+}, \mathrm{K}^{+}$and $\mathrm{Ca}^{2+}$.

\section{Conclusions}

In this paper, CST was successfully prepared by sol-gel and hydrothermal treatment using waste CRT panel glass as silicon source extracted by $\mathrm{SCW}-\mathrm{NaOH}$ process. In the extraction process, supercritical water could destroy the glass network, hence Si could efficiently transfer into the solution with an efficiency of $80 \%$, while $\mathrm{Sr}$ and $\mathrm{Ba}$ were enriched in the residue in the form of $\mathrm{Sr}_{2} \mathrm{SiO}_{4}$ and $\mathrm{Ba}_{2} \mathrm{Si}_{3} \mathrm{O}_{8}$.

After the extraction process, $\mathrm{Sr}$ and Ba contents in the residue were about 2-3 times higher than those in the original glass. The residue has the potential to be used as a raw material for metallic $\mathrm{Ba}$ and $\mathrm{Sr}$ metallurgy, and the liquid could be used as a silicon source for CST synthesis. The synthesized CST could be used as an inorganic ion exchanger for $\mathrm{Cs}^{+}$removal from aqueous system with a distribution coefficient of up to $1.2 \times 10^{4} \mathrm{~mL} / \mathrm{g}$.

\section{Acknowledgements}

This work was financially supported, in part, by the National Basic Research Program of China with a funding number of 2007CB407303 and National Natural Science Foundation of China with a funding number of 50708110 .

\section{References}

[1] F. Méar, P. Yot, M. Cambon, M. Ribes, The characterization of waste cathode-ray tube glass, Waste Manage. 26 (2006) 1468-1476.

[2] S.E. Musson, Y.C. Jang, T.G. Townsend, I.H. Chung, Characterization of lead leachability from cathode ray tubes using the toxicity characteristic leaching procedure, Environ. Sci. Technol. 34 (2000) 4376-4381.

[3] The Basel Action Network (BAN), The Silicon Valley Coalition (SVTC), Toxics Link India, SCOPE (Pakistan), Greanpeace China, Exporting Harm: The High-tech Trashing of Asia, http://www.svtc.org/cleance/pubs/technotrash.pdf, 2002.

[4] F. Andreola, L. Barbieri, A. Corradi, I. Lancellotti, Cathode ray tube glass recycling: an example of clean technology, Waste Manage. Res. 23 (2005) 314321.

[5] F. Andreola, L. Barbieri, A. Corradi, E. Karamanova, I. Lancelloti, M. Pelino, Recycling of CRT panel glass as fluxing agent in the porcelain stoneware tile production, Ceram. Int. 34 (2008) 1289-1295.

[6] E. Bernardo, Micro- and macro-cellular sintered glass-ceramics from wastes, J. Eur. Ceram. Soc. 27 (2007) 2415-2422.

[7] E. Bernardo, F. Albertini, Glass foams from dismantled cathode ray tubes, Ceram. Int. 32 (2006) 603-608.

[8] Z. Matamoros-Veloza, J.C. Rendón-Angeles, K. Yanagisawa, M.A. CisnerosGuerrero, M.M. Cisneros-Guerrero, L. Aguirre, Preparation of foamed glasses from CRT TV glass by means of hydrothermal hot-pressing technique, J. Eur. Ceram. Soc. 28 (2008) 739-745.

[9] F. Méar, P. Yot, M. Cambon, M. Ribes, Elaboration and characterisation of foam glass from cathode ray tubes, Adv. Appl. Ceram. 104 (2005) 123-130.

[10] F. Méar, P. Yot, M. Ribes, Effects of temperature, reaction time and reducing agent content on the synthesis of macroporous foam glasses from waste funnel glasses, Mater. Lett. 60 (2006) 929-934.

[11] E. Bernardo, R. Cedro, M. Florean, S. Hreglich, Reutilization and stabilization of wastes by the production of glass foams, Ceram. Int. 33 (2007) 963-968.

[12] F. Méar, P. Yot, R. Viennois, M. Ribes, Mechanical behaviour and thermal and electrical properties of foam glass, Ceram. Int. 33 (2007) 543-550.
[13] E. Bernardo, G. Scarinci, Sintering behaviour and mechanical properties of $\mathrm{Al}_{2} \mathrm{O}_{3}$ platelet-reinforced glass matrix composites obtained by powder technology, Ceram. Int. 30 (2004) 785-791.

[14] E. Bernardo, G. Scarinci, S. Hreglich, Mechanical properties of metal-particulate lead-silicate glass matrix composites obtained by means of powder technology, J. Eur. Ceram. Soc. 23 (2003) 1819-1827.

[15] E. Bernardo, G. Scarinci, S. Hreglich, Development and mechanical characterization of $\mathrm{Al}_{2} \mathrm{O}_{3}$ platelet-reinforced glass matrix composites obtained from glasses coming from dismantled cathode ray tubes, J. Eur. Ceram. Soc. 25 (2005) 1541-1550.

[16] E.J. Minay, V. Desbois, A.R. Boccaccini, Innovative manufacturing technique for glass matrix composites: extrusion of recycled TV set screen glass reinforced with $\mathrm{Al}_{2} \mathrm{O}_{3}$ platelets, J. Mater. Process. Technol. 142 (2003) 471-478.

[17] D. Kim, I.G. Petrisor, T.F. Yen, Evaluation of biopolymer-modified concrete systems for disposal of cathode ray tube glass, J. Air Waste Manage. Assoc. 55 (2005) 961-969.

[18] F. Méar, P. Yot, M. Cambon, M. Ribes, The changes in lead silicate glasses induced by the addition of a reducing agent (TiN or SiC), J. Non-Cryst. Solids 351 (2005) 3314-3319.

[19] H. Miyoshi, D.P. Chen, T. Akai, A novel process utilizing subcritical water to remove lead from wasted lead silicate glass, Chem. Lett. 33 (2004) 956-957.

[20] A.J. Saterlay, S.J. Wilkins, R.G. Compton, Towards greener disposal of waste cathode ray tubes via ultrasonically enhanced lead leaching, Green Chem. 3 (2001) 149-155.

[21] M. Chen, F.S. Zhang, J. Zhu, Lead recovery and the feasibility of foam glass production from funnel glass of dismantled cathode ray tube through pyrovacuum process, J. Hazard. Mater. 161 (2009) 1109-1113.

[22] R.G. Anthony, R.G. Dosch, D. Gu, C.V. Philip, use of silicotitanates for removing cesium and strontium from defense waste, Ind. Eng. Chem. Res. 33 (1994) 2702-2705.

[23] Z.X.Zheng, D. Gu, R.G. Anthony, E. Klavetter, Estimation of cesium ion-exchange distribution coefficients for concentrated electrolytic solutions when using crystalline silicotitanates, Ind. Eng. Chem. Res. 34 (1995) 2142-2147.

[24] D. Gu, L. Nguyen, C.V. Philip, M.E. Huckman, R.G. Anthony, J.E. Miller, D.E. Trudell, $\mathrm{Cs}^{+}$ion exchange kinetics in complex electrolyte solutions using hydrous crystalline silicotitanates, Ind. Eng. Chem. Res. 36 (1997) 5377-5383.

[25] M.E. Huckman, I.M. Latheef, R.G. Anthony, Ion exchange of several radionuclides on the hydrous crystalline silicotitanate, UOP IONSIV IE-911, Sep. Sci. Technol. 34 (1999) 1145-1166.

[26] J.F. Walker, P.A. Taylor, D.D. Lee, Cesium removal from high-pH, high-salt wastewater using crystalline silicotitanate sorbent, Sep. Sci. Technol. 34 (1999) 1167-1181.

[27] A.J. Celestian, J.D. Kubicki, J. Hanson, A. Clearfield, J.B. Parise, The mechanism responsible for extraordinary Cs ion selectivity in crystalline silicotitanate, J. Am. Chem. Soc. 130 (2008) 11689-11694.

[28] A.J. Celestian, A. Clearfield, The origin of ion exchange selectivity in a porous framework titanium silicate, J. Mater. Chem. 17 (2007) 4839-4842.

[29] A. Tripathi, D.G. Medvedev, M. Nyman, A. Clearfield, Selectivity for Cs and Sr in Nb-substituted titanosilicate with sitinakite topology, J. Solid State Chem. 175 (2003) 72-83.

[30] M.K. Andreus, P.J. Workman, Glass formulation development and testing for the vitrification of DWPF HLW sludge coupled with crystalline silicotitanate (CST), http://www.osti.gov/bridge/servlets/purl/564994UfOBUJ/webviewable/564994.pdf, 1997.

[31] B. Yu, J. Chen, C.L. Song, Crystalline silicotitanate: a new type of ion exchanger for Cs removal from liquid waste, J. Mater. Sci. Technol. 18 (2002) 206-210.

[32] T. Tomasberger, A.C. Veltkamp, A.S. Booij, U.W. Scherer, Radiocesium removal from high level liquid waste and immobilisation in sodium silicotitanate for geological disposal, Radiochim. Acta 89 (2001) 145-149.

[33] D.M. Poojary, R.A. Cahill, A. Clearfield, Synthesis, crystal structures, and ionexchange properties of a novel porous titanosilicate, Chem. Mater. 6 (1994) 2364-2368.

[34] M. Nyman, B.X. Gu, L.M. Wang, R.C. Ewing, T.M. Nenoff, Synthesis and characterization of a new microporous cesium silicotitanate (SNL-B) molecular sieve, Micropor. Mesopor. Mater. 40 (2000) 115-125.

[35] A.J. Celestian, D.G. Medvedev, A. Tripathi, J.B. Parise, A. Clearfield, Optimizing synthesis of $\mathrm{Na}_{2} \mathrm{Ti}_{2} \mathrm{SiO}_{7} \cdot 2 \mathrm{H}_{2} \mathrm{O}$ (Na-CST) and ion exchange pathways for $\mathrm{Cs}_{0.4} \mathrm{H}_{1.6} \mathrm{Ti}_{2} \mathrm{SiO}_{7} \cdot \mathrm{H}_{2} \mathrm{O}$ (Cs-CST) determined from in situ synchrotron X-ray powder diffraction, Nucl. Instrum. Methods Phys. Res. Sect. B: Beam Interact. Mater. Atom 238 (2005) 61-69.

[36] S. Yamasaki, Digestion method for total element analysis, in: Method of Soil Environmental Analysis, Japanese Society of Soil Science and Plant Nutrition, Hakuyusya, Tokyo, 1997, pp. 278-288 (in Japanese).

[37] R. Harjula, A. Dyer, S.D. Pearson, R.P. Townsend, J. Chem. Soc.: Faraday Trans. 89 (1993) 1491.

[38] F.S. Zhang, H. Itoh, A novel process utilizing subcritical water and nitrilotriacetic acid to extract hazardous elements from MSW incinerator fly ash, Sci. Total Environ. 369 (2006) 273-279.

[39] J.R. Zhang, Preparation of Crystalline Silicotitanate (CST) and its Exchanging Characteristics to $\mathrm{Cs}^{+}$in Acid Conditions, Tsinghua University, 2000 (in Chinese). 